\title{
Respiratory Function during Sleep in Patients with Chronic Obstructive Lung Disease *
}

\author{
Alan K. Pierce, $\dagger$ Charles E. Jarrett, $\ddagger$ George Werkle, Jr., and \\ William F. Miller \\ (From the Cardiopulmonary Laboratory, Department of Internal Medicine, The University of \\ Texas Southwestern Medical School, Dallas, Texas)
}

Hypoventilation of normal persons during sleep causes the arterial carbon dioxide tension to rise (1-9). Hypoventilation during sleep is accentuated when the respiratory center is further depressed by opiates (10); it might be suspected that carbon dioxide retention during sleep would be similarly accentuated in patients with chronic hypercapnia. Indeed, available evidence suggests that such patients with chronic obstructive pulmonary disease demonstrate even more marked hypoventilation while asleep than that seen in normal persons $(11,12)$. This study was undertaken to determine the extent of hypoventilation in sleeping patients with chronic obstructive pulmonary disease. The study also presented the opportunity to determine the mechanisms responsible for the hypoxia sometimes seen in such patients (13) and to determine the ventilatory pattern during sleep.

\section{Methods}

The only criteria for selection of subjects were availability and the presence of severe chronic airway obstruction. The first 11 patients were studied during the evening hours. These patients were brought to the laboratory shortly before their accustomed hour of sleep ( 8 to 11 p.m.). The next 8 patients were studied in the early afternoon after a light lunch (1 to 3 p.m.). No

* Submitted for publication May 26, 1965; accepted December 29, 1965.

These studies were supported in part by U. S. Public Health Service grant HE-05167-05 and training grant 5T1 HE-5396-05 from the National Heart Institute.

Presented in part before the Pulmonary Section of the Twenty-second Annual Meeting of the American Federation for Clinical Research, Atlantic City, N. J., May 1965.

$\dagger$ Recipient of U. S. Public Health Service postdoctoral fellowship HPD-17528.

Address requests for reprints to Dr. Alan K. Pierce, Dept. of Internal Medicine, University of Texas Southwestern Medical School, Dallas, Texas 75235.

$\ddagger$ Recipient of U. S. Public Health Service postdoctoral fellowship 1F2HE-20, 301-01. medication was given any patient to induce sleep, and all other medications were withheld for the 4 hours before the onset of the study.

When each patient reported to the laboratory, aerosol bronchodilator $(2.5 \mathrm{mg}$ isoproterenol and $5.0 \mathrm{mg}$ cyclopentamine) was administered by an intermittent positive pressure breathing device. Approximately 15 minutes after the termination of the bronchodilator treatment, the patient performed a forced spirogram, and the various timed segments, flow rates, and volumes were determined in the usual way (14). Parietal and occipital electroencephalogram (EEG) electrodes were then attached with electrode cream; electrocardiogram electrodes were fastened in position at the shoulders and thighs with bentonite paste and colloiden gel. A pneumatic cuff pressure transducer apparatus was connected to the patient's chest for the subsequent determination of respiratory movement. The patient was then placed in bed, and all of this apparatus was connected to a multichannel direct-writing recorder. When it was determined that all systems were operative, a Cournand needle was placed in a brachial artery, and that arm was secured with tape to a padded board. The patient was allowed to return to a stable state of basal respirations at which time base-line blood for gas analysis was drawn during EEG-monitored wakefulness. The lights were then subdued, and the patient was left undisturbed. During the entire study the patient was observed by one of the investigators, who noted changes in the patient's position, respiration, and clinical alertness. The recorder paper ran at $25 \mathrm{~mm}$ per second during most of the study period.

Blood for gas analysis was periodically drawn into sealed, heparinized syringes that were then occluded with a mercury cap. Analytic determinations were carried out within 15 minutes of obtaining each specimen. $\mathrm{pH}$ was measured at $37^{\circ} \mathrm{C}$ with a Sands type Metrohm electrode and arterial carbon dioxide tension $\left(\mathrm{Paco}_{2}\right)$ with a Severinghaus electrode (15) ; the output of each of these electrodes was read with a model C33B Vibron electrometer. Oxygen saturation was measured by determining the ratio of the light intensities diffusely backscattered from whole blood at 2 wavelengths of light on each of two American Optical Company oximeters and was required to measure within $1 \%$ on the two machines. These oximeters were regularly standardized with a Clark oxygen electrode. 
Others have emphasized $(4,7)$ that the breath-by-breath analysis of expired $\mathrm{CO}_{2}$ by a rapid-acting infrared spectrophotometer is the ideal way of following the level of $\mathrm{CO}_{2}$ for an extended period of time. Unfortunately, this method is not satisfactory in patients with lung disease who have uneven ventilation-perfusion relationships; in such patients, the end-tidal $\mathrm{CO}_{2}$ is not an adequate reflection of $\mathrm{PaCO}_{2}$. We have therefore relied on multiple samples of arterial blood. An average of 10.7 samples of blood was obtained from the nocturnal sleepers during the study or a sample every 12 minutes. An average of 5.3 samples or a sample every 15.5 minutes was collected from day sleepers. Although instantaneous changes in blood gases may have been missed, this sampling technique is certainly sufficient to determine trends.

The electroencephalograms were read by an independent observer who noted the depth of sleep every 12.5 seconds according to the criteria of Loomis, Harvey, and Hobart (16), as modified by Simon and Emmons (17). By these criteria stage 0 corresponds to wakefulness, stage A to drowsiness, stage $B$ to a transition state, stage $C$ to light sleep, stage $D$ to deep sleep, and stage $E$ to very deep sleep.

Student's $t$ test was used to determine the significance of the difference between the various observations reported (18). Results were considered not significant if the likelihood of occurrence by chance alone was greater than $5 \%(p>0.05)$. Since there was no statistical difference between the day and night sleepers as regards any measurement of waking ventilation or any of the sleeping functions, these groups will be reported together.

\section{Results}

The age, ventilatory functions, and blood gas values while awake of the 19 men in this study are recorded in Table I. All of the patients had severe obstructive ventilatory defects. There was no correlation between the magnitude of the ventilatory defect in each patient and the change with sleep of the various functions reported. Only two patients (10 and 18) had normal oxygen saturations $(\geq 95 \%)$ while awake. Ten patients had definite hypercapnia while awake $\left(\mathrm{Pa}_{\mathrm{CO}_{2}}>45\right.$ $\mathrm{mm} \mathrm{Hg}$ ).

Despite the various monitoring equipment used, no patient failed to sleep. Only one (Patient 1) failed to reach stage $\mathrm{C}$ of sleep or deeper; conversely, only one (Patient 14) reached stage $E$ of sleep. The nocturnal subjects were asleep on the average longer than the afternoon sleepers (136 and 83 minutes, respectively).

In each case the $\mathrm{Pa}_{\mathrm{CO}_{2}}$ rose during sleep ( Table II). In no case was this rise greater than 12 $\mathrm{mm} \mathrm{Hg}$, and the mean maximal rise was $6.6 \mathrm{~mm}$ $\mathrm{Hg}$. The mean maximal fall in $\mathrm{pH}$ was 0.02 . The mean maximal rise in calculated plasma bicarbonate concentration was $2 \mathrm{mEq}$ per $\mathrm{L}$, which

TABLE I

Pulmonary functions and blood gases in subjects while awake*

\begin{tabular}{|c|c|c|c|c|c|c|c|c|c|}
\hline Patient & Age & PVC & FVC & FEV $_{1.0}$ & $\mathrm{FEF}_{25-75} \%$ & FIF & $\begin{array}{l}\text { Wake } \\
\mathrm{Sa}_{\mathrm{O}_{2}}\end{array}$ & $\begin{array}{l}\text { Wake } \\
\mathrm{Pa}_{\mathrm{CO}_{2}}\end{array}$ & $\underset{\mathrm{pH}}{\text { Wake }}$ \\
\hline & years & $L$ & $L$ & $L$ & $L / \mathrm{sec}$ & $L / \sec$ & $\%$ & $m m \mathrm{Hg}$ & \\
\hline 1 & 67 & 4.07 & 3.60 & 1.54 & 0.58 & 3.30 & 91 & 39 & 7.40 \\
\hline 2 & 59 & 4.33 & 4.25 & 1.02 & 0.42 & 3.39 & 92 & 44 & 7.36 \\
\hline 3 & 62 & 3.86 & 2.28 & 0.83 & 0.20 & 2.24 & 94 & 45 & 7.41 \\
\hline 4 & 61 & 4.16 & 3.10 & 1.32 & 0.43 & 4.43 & 83 & 54 & 7.39 \\
\hline 5 & 74 & 3.35 & 2.14 & 0.90 & 0.40 & 1.69 & 83 & 61 & 7.39 \\
\hline 6 & 61 & 3.89 & 3.71 & 1.30 & 0.33 & 5.16 & 94 & 41 & 7.45 \\
\hline 7 & 71 & 3.56 & 2.66 & 0.94 & 0.35 & 3.14 & 92.5 & 51 & 7.36 \\
\hline 8 & 54 & 4.03 & 1.89 & 0.40 & 0.14 & 1.34 & 93.5 & 44 & 7.41 \\
\hline 9 & 58 & 4.33 & 2.88 & 0.73 & 0.26 & 2.17 & 82.5 & 72 & 7.35 \\
\hline 10 & 74 & 3.64 & 2.04 & 0.93 & 0.44 & 2.16 & 95 & 33 & 7.43 \\
\hline 11 & 61 & 4.12 & 1.66 & 0.34 & 0.16 & 0.82 & 87 & 45 & 7.38 \\
\hline 12 & 51 & 4.52 & 3.16 & 0.96 & 0.31 & 4.37 & 84 & 57 & 7.40 \\
\hline 13 & 68 & & 2.44 & 0.64 & 0.29 & 4.60 & 93 & 44 & 7.42 \\
\hline 14 & 47 & 4.13 & 2.67 & 1.03 & 0.31 & 4.01 & 88 & 61 & 7.43 \\
\hline 15 & 59 & & & & & & 94 & 49 & 7.39 \\
\hline 16 & 65 & 4.23 & 3.70 & 1.95 & 0.75 & $2.80^{\circ}$ & 93.5 & 46 & 7.37 \\
\hline 17 & 57 & 3.95 & 2.96 & 1.78 & 0.78 & 2.63 & 94 & 36 & 7.39 \\
\hline 18 & 69 & 3.22 & 1.35 & 0.70 & 0.38 & 2.63 & 96 & 37 & 7.38 \\
\hline 19 & 59 & 3.60 & 2.02 & 1.40 & 1.07 & 2.60 & 94 & 44 & 7.46 \\
\hline Average & 62 & 3.94 & 2.69 & 1.03 & 0.39 & 2.97 & 90.7 & 47.5 & 7.39 \\
\hline
\end{tabular}

* Abbreviations: PVC, predicted vital capacity; FVC, forced vital capacity; $\mathrm{FEV}_{1.0}$, forced expiratory volume in 1.0 second (normal value, $>75 \%$ of $\mathrm{FVC}$ ) $\mathrm{FEF}_{25-75 \%}$, forced expiratory flow during the first one-fourth of the vital capacity (normal range, 4.5 to 10.7); FIF, forced inspiratory flow (normal range, 4.2 to 5.9); Sa $\mathrm{O}_{2}$, oxygen saturation (normal value, $\geq 95 \%$ ); $\mathrm{PaCO}_{2}$, arterial carbon dioxide tension (normal value, $40 \pm 5$ ). 
TABLE II

Blood gases during sleep

\begin{tabular}{|c|c|c|c|c|c|c|c|}
\hline Patient & 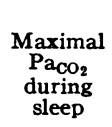 & $\begin{array}{c}\text { Maximal } \\
\mathrm{PaCO}_{2} \\
\text { rise } \\
\text { during } \\
\text { sleep }\end{array}$ & $\begin{array}{c}\text { Lowest } \\
\text { pH } \\
\text { during } \\
\text { sleep }\end{array}$ & $\begin{array}{c}\text { Marimal } \\
\text { pH } \\
\text { fall } \\
\text { during } \\
\text { sleep }\end{array}$ & $\begin{array}{c}\text { Lowest } \\
\text { Saoz } \\
\text { during } \\
\text { sleep }\end{array}$ & $\begin{array}{c}\text { Maximal } \\
\mathrm{Sa}_{2} \\
\text { fall } \\
\text { during } \\
\text { sleep }\end{array}$ & $\begin{array}{c}\text { Maximal } \\
\mathrm{PaO}_{2} \\
\text { fall } \\
\text { during } \\
\text { sleep }\end{array}$ \\
\hline & $m m H g$ & $m m H g$ & & & $\%$ & $\%$ & $m m \boldsymbol{H g}$ \\
\hline 1 & 45 & 6 & 7.39 & 0.01 & 89.0 & 2.0 & 4 \\
\hline 2 & 53 & 9 & 7.33 & 0.03 & 82.0 & 10.0 & 18 \\
\hline 3 & 55 & 10 & 7.36 & 0.05 & 87.0 & 7.0 & 16 \\
\hline 4 & 64 & 10 & 7.37 & 0.02 & 77.0 & 6.0 & 6 \\
\hline 5 & 65 & 4 & 7.38 & 0.01 & 73.0 & 10.0 & 9 \\
\hline 6 & 42 & 6 & 7.42 & 0.03 & 91.0 & 3.0 & 8 \\
\hline 7 & 58 & 7 & 7.32 & 0.04 & 88.0 & 4.5 & 9 \\
\hline 8 & 49 & 5 & 7.40 & 0.01 & 91.0 & 2.5 & 7 \\
\hline 9 & 74 & 7 & 7.34 & 0.01 & 63.0 & 19.5 & 16 \\
\hline 10 & 42 & 9 & 7.37 & 0.01 & 92.5 & 2.5 & 9 \\
\hline 11 & 48 & 3 & 7.35 & 0.03 & 83.5 & 3.5 & 5 \\
\hline 12 & 65 & 7 & 7.37 & 0.03 & 77.0 & 7.0 & 8 \\
\hline 13 & 47 & 3 & 7.41 & 0.01 & 92.0 & 1.0 & 2 \\
\hline 14 & 68 & 10 & 7.38 & 0.05 & 79.0 & 9.0 & 10 \\
\hline 15 & 50 & 1 & 7.39 & 0.00 & 94.0 & 0.0 & 0 \\
\hline 16 & 49 & 5 & 7.36 & 0.01 & 91.0 & 2.5 & 6 \\
\hline 17 & 48 & 12 & 7.38 & 0.01 & 93.0 & 1.0 & 3 \\
\hline 18 & 39 & 1 & 7.36 & 0.02 & 96.0 & 0.0 & 0 \\
\hline 19 & 55 & 11 & 7.40 & 0.06 & 91.0 & 3.0 & 6 \\
\hline Average & 53 & 7 & 7.37 & 0.02 & 85.7 & 4.9 & 7 \\
\hline
\end{tabular}

is well within the expected rise for this degree of acute hypercapnia (19). The $\mathrm{Pa}_{\mathrm{CO}_{2}}$ was higher in the deeper stages of sleep (Figure 1); the variability in $\mathrm{Pa}_{\mathrm{CO}_{2}}$ at any particular stage of sleep was large in some patients.

In 17 of the 19 subjects the oxygen saturation during one or more of the samples taken while subjects were sleeping was lower than values while they were awake (Table II). There was considerable variability in the oxygen saturation during the course of the sleeping period. In some cases the oxygen saturation remained below the waking level during the entire period of sleep and rose on waking to values before sleep, whereas on other occasions, the oxygen saturation fell and then rose again to waking values during the course of sleep. These fluctuations did not correlate with movement or position. There was a tendency for the patients with the lowest waking oxygen saturations to have the greatest falls in sleeping saturations, but this was not invariable (Tables I and II). The oxygen tension did not fall progressively with the deeper levels of sleep; indeed, the lowest tensions occurred in stage $\mathrm{B}$, and the tensions returned toward waking values in stages $C$ and $D$ (Figure 1). The very large falls in oxygen saturation are misleading in terms of altered pulmonary function. Since the oxygen saturations

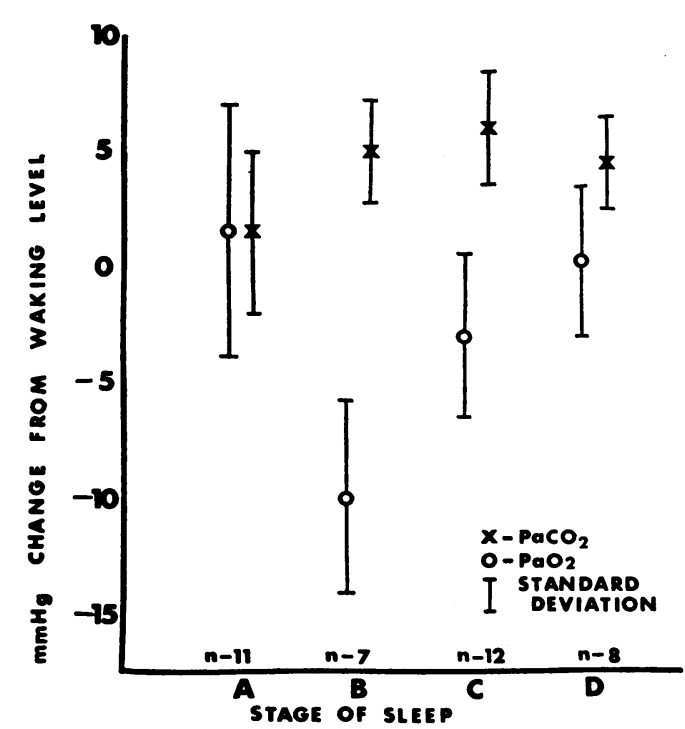

Fig. 1. Changes in blood gas tensions with sleep. Only the blood samples obtained after the patient had been in a single stage of sleep for at least 4 minutes were recorded. Levels of significance between the means follow (see Methods for explanation of stages of sleep). $\mathrm{Pa}_{0_{2}}$-stages $\mathrm{A}$ to $\mathrm{B}, \mathrm{B}$ to $\mathrm{C}$, and $\mathrm{B}$ to $\mathrm{D}, \mathrm{p}<0.001$; stage $A$ to $C, p<0.05$; stage $C$ to $D, 0.1>p>0.05$. All other relationships of $\mathrm{Pa}_{2}$ were not significantly different. $\mathrm{Paco}_{2}$-stages $\mathrm{A}$ to $\mathrm{B}$ and $\mathrm{A}$ to $\mathrm{C}, \mathrm{p}<0.001$; stage $A$ to $D, 0.1>p>0.05$. All other relationships of $\mathrm{Paco}_{2}$ were not significantly different. 
TABLE III

Heart rates during sleep

\begin{tabular}{crrrrr}
\hline \hline & \multicolumn{5}{c}{ EEG stage of sleep* } \\
\cline { 2 - 6 } Patient & \multicolumn{1}{c}{ 0 } & \multicolumn{1}{c}{ A } & \multicolumn{1}{c}{ B } & \multicolumn{1}{c}{ C } & D \\
\hline 3 & 74.1 & 78.6 & 73.0 & 72.6 & \\
4 & 86.2 & 82.0 & 84.0 & 82.4 & \\
5 & & 110.3 & 107.0 & 108.5 & \\
6 & 85.8 & 81.5 & 82.8 & 79.0 & \\
7 & 85.2 & 83.1 & 80.2 & 79.8 & \\
8 & 69.0 & 70.5 & 64.8 & 64.1 & 62.8 \\
9 & 97.8 & 94.6 & & 97.4 & 93.5 \\
10 & 69.0 & 71.6 & 72.8 & 73.5 & \\
11 & 76.6 & 72.4 & & 67.8 & \\
12 & & 75.6 & 77.6 & 89.5 & \\
13 & & 106.0 & 103.0 & 101.5 & 106.4 \\
14 & & 74.2 & 75.8 & 72.8 & \\
15 & & 64.7 & 66.9 & 68.1 & \\
16 & & 74.8 & 73.6 & & \\
17 & & 94.2 & 90.7 & 87.7 & \\
18 & & 93.7 & 91.6 & 89.0 & \\
19 & & 82.9 & 82.1 & 81.4 & \\
Average & 80.4 & & & & \\
\hline
\end{tabular}

* See Methods for explanation.

tended to be rather low in the waking state, the large changes in saturation were brought about by relatively small changes in the arterial oxygen tension $\left(\mathrm{Pa}_{\mathrm{O}_{2}}\right)$ because of the shape of the oxygen dissociation curve. In addition, the changing $\mathrm{pH}$ associated with the rising $\mathrm{Pa}_{\mathrm{CO}_{2}}$ shifts the dissociation curve to the right. The mean maximal change in $\mathrm{Pa}_{\mathrm{O}_{2}}$ from wake to sleep was only $7.4 \mathrm{~mm} \mathrm{Hg}$ ( SD \pm 5.0 ).

The heart rate during sleep was quite variable from subject to subject, but it remained relatively stable in any given subject. Replicate measurements were available for all patients at several stages of sleep, and the range in pulse rate for an individual in one stage of sleep averaged 8.7 beats per minute. There was no significant change in pulse rate from wake to sleep ( $p>0.5)$. Moreover, during sleep there was no consistent tendency for the heart rate to change (mean change from stage A to stage $\mathrm{C},-1.5, \mathrm{p}>0.7$ ) (Table III). Patients with a mean sleeping oxygen saturation of less than $85 \%$ had a mean sleeping pulse greater than 81 , whereas only two of the twelve patients with a mean arterial oxygen saturation during sleep greater than $85 \%$ had this high a mean pulse rate $(p<0.01)$.

The respiratory rate was not only quite variable from subject to subject, but also varied considerably from time to time in any individual subject. For any one individual during sleep the range in respiratory rate averaged 6.3 breaths per minute. There was no significant change in respiratory rate as the subject passed from wakefulness to sleep $(p>0.3)$ (Table IV). Moreover, there was no consistent tendency for respiratory rate to change in relation to changes in the depth of sleep (mean change from stage A to stage $\mathrm{C}, 1.8, \mathrm{p}>$ $0.3)$. The variability in the respiratory rate tended to occur as a subject changed from one level of sleep to another. As a subject remained in any level of sleep, the respiratory rate became monotonously regular. Patients with an oxygen saturation greater than $85 \%$ had a mean sleeping respiratory rate of 18.1 ( $\mathrm{SD} \pm 2.9$ ), whereas patients with a sleeping oxygen saturation of less than $85 \%$ had a mean sleeping respiratory rate of 25.8 ( $\mathrm{SD} \pm 6.4, \mathrm{p}<0.001$ ).

\section{Discussion}

Normal subjects consistently show a rise in $\mathrm{P}_{\mathrm{CO}_{2}}$ during sleep due to a diminished responsiveness of the respiratory center to carbon dioxide. and the greater the depth of sleep the more marked the rise (3-7). Because this occurs so rapidly with the onset of sleep, it is thought to be a neurogenic effect. Increases in $\mathrm{PA}_{\mathrm{CO}_{2}}$ in normal subjects have been reported as high as $14 \mathrm{~mm} \mathrm{Hg}$, and a rise of $10 \mathrm{~mm} \mathrm{Hg}$ is not uncommon. In the series of normal subjects reported by Robin,

TABLE IV

Respiratory rate during sleep

\begin{tabular}{cccccc}
\hline \hline & \multicolumn{5}{c}{ EEG stage of sleep } \\
\cline { 2 - 6 } Patient & 0 & A & B & C & D \\
\hline 1 & 13.7 & 14.9 & 15.5 & & \\
2 & 20.7 & 19.5 & 17.4 & & \\
3 & 15.3 & 16.1 & 17.7 & 16.5 & \\
4 & 17.9 & 22.3 & 23.0 & 23.0 & 23.8 \\
5 & & 29.1 & 27.8 & 34.3 & \\
6 & 15.7 & 21.0 & 23.5 & 23.7 & \\
7 & 16.6 & 13.8 & 16.2 & 16.1 & \\
8 & 13.3 & 19.4 & 20.1 & 19.9 & 19.6 \\
9 & 24.8 & 20.8 & & 20.1 & 19.9 \\
10 & 19.0 & 16.6 & 16.4 & 20.0 & \\
11 & 15.5 & 15.9 & & 18.0 & \\
12 & & 21.1 & 13.6 & 29.2 & 32.3 \\
13 & & 21.8 & 21.0 & \\
14 & & 21.7 & 33.0 & 35.5 & 37.7 \\
15 & & 17.7 & 15.3 & 13.9 & \\
16 & & 17.2 & 16.7 & 13.3 & \\
17 & & 23.2 & 18.8 & 17.5 & \\
18 & & 13.7 & 16.3 & 14.2 & \\
19 & & 19.3 & 19.7 & 21.1 & 26.6 \\
Average & 17.3 & 19.3 & & & \\
\hline
\end{tabular}


Whaley, Crump, and Travis (4) the mean maximal rise in $\mathrm{PACO}_{2}$ was $8.0 \mathrm{~mm} \mathrm{Hg}$, whereas in the series by Birchfield, Sieker, and Heyman $(3,5)$ the mean rises in $\mathrm{Pa}_{\mathrm{CO}_{2}}$ were 5.3 and $4.1 \mathrm{~mm} \mathrm{Hg}$. These rises are not significantly different from our mean maximal rise of $6.6 \mathrm{~mm} \mathrm{Hg}(\mathrm{p}>0.2)$. Moreover, in none of our patients was there a $\mathrm{Pa}_{\mathrm{CO}_{2}}$ rise greater than $12 \mathrm{~mm} \mathrm{Hg}$. It is not known whether the physiological effects of a given rise in $\mathrm{Pa}_{\mathrm{CO}_{2}}$ differ from usual when the initial $\mathrm{Pa}_{\mathrm{CO}_{2}}$ is elevated. Nevertheless, our data do not support the contention that the patient with chronic pulmonary disease shows greater $\mathrm{CO}_{2}$ elevations and a more profound depression of respiratory center sensitivity during sleep than do normal subjects $(11,12)$.

It would be reasonable to expect depressed ventilation, accompanied by relatively infrequent movement and frequently associated with obstructing mucus in the airways, to be associated with an abnormal distribution of ventilation in relation to blood flow. The $\mathrm{Pa}_{\mathrm{O}_{2}}$ fell maximally in the middle stage of sleep and during deeper sleep rose again to waking levels. The initial fall in $\mathrm{Pa}_{\mathrm{O}_{2}}$ coincided with the rise in $\mathrm{Pa}_{\mathrm{CO}_{2}}$, but the subsequent rise in $\mathrm{Pa}_{2}$ occurred despite the persistent elevation of $\mathrm{Pa}_{\mathrm{CO}_{2}}$. Therefore, ventilation-perfusion relationships must have improved in the deeper stages of sleep. This unexpected finding is probably related to a more efficient pattern of ventilation during the deeper stages of sleep. This observation deserves further investigation.

It is apparent from these data that the mean maximal fall in $\mathrm{Pa}_{2}$ from wake to sleep was only $7.4 \mathrm{~mm} \mathrm{Hg}(\mathrm{SD} \pm 5.0)$. Only Birchfield and his associates $(3,5)$ have reported comparable oxygen saturations and $\mathrm{pH}$ during wake and sleep. Of their 22 normal subjects, 14 had a modest reduction in oxygen saturation during sleep. The calculated change in $\mathrm{Pa}_{\mathrm{O}_{2}}$ from wake to sleep in these 22 subjects was $4.9 \mathrm{~mm} \mathrm{Hg}$. This change in $\mathrm{Pa}_{\mathrm{O}_{2}}$ is not significantly different from the change observed in this series $(p>0.3)$. Thus the hypoxia noted in these patients, as suggested by others (12, 13 ), is a manifestation of the greater change in oxygen saturation per unit change in $\mathrm{Pa}_{O_{2}}$ when the oxygen saturation is on the steep segment of the oxygen dissociation curve.

It is significant that all of our patients with oxygen saturations less than $85 \%$ had a tachycardia during sleep. Severe hypoxia is known to cause tachycardia (20) and pulmonary hypertension (21), and these events are important in the genesis of cor pulmonale. The present data suggest that adequate oxygenation during sleep, if accentuation of hypoventilation did not occur, might defer the appearance of cor pulmonale in patients such as these.

\section{Summary}

The heart rate, respiratory rate, and blood gases have been followed during the course of electroencephalogram-monitored sleep in 19 men with chronic obstructive lung disease. No patient had a greater rise in arterial carbon dioxide tension during sleep than occurs in normal subjects. However, the patients had an average maximal decrease in arterial oxygen saturation during sleep of $5 \%$. A significant tachycardia was observed in sleeping patients with an oxygen saturation of less than $85 \%$.

\section{Acknowledgments}

We wish to thank Dr. Paul Grider for his meticulous reading of the electroencephalograms; Mrs. Ann Williams and Mr. Robert Felder for their technical assistance; and Mrs. Shirley Gross, Mrs. Penelope Coates, and Mrs. Scharmel Johnson for their clerical aid.

\section{References}

1. Kleitman, N. Sleep and Wakefulness, 2nd ed. Chicago, University of Chicago Press, 1963.

2. Mills, J. N. Changes in alveolar carbon dioxide tension by night and during sleep. J. Physiol. (Lond.) $1953,122,66$.

3. Birchfield, R. I., H. O. Sieker, and A. Heyman. A1terations in blood gases during natural sleep and narcolepsy. A correlation with the electroencephalographic stages of sleep. Neurology (Minneap.) 1958, 8, 107.

4. Robin, E. D., R. D. Whaley, C. H. Crump, and D. M. Travis. Alveolar gas tensions, pulmonary ventilation and blood $\mathrm{pH}$ during physiologic sleep in normal subjects. J. clin. Invest. 1958, 37, 981.

5. Birchfield, R. I., H. O. Sieker, and A. Heyman. Alterations in respiratory function during natural sleep. J. Lab. clin. Med. 1959, 54, 216.

6. Sieker, H. O., A. Heyman, and R. I. Birchfield. The effects of natural sleep in hypersomnolent states on respiratory function. Ann. intern. Med. 1960, 52,500 .

7. Bülow, K. Respiration and wakefulness in man. Acta physiol. scand. 1963, 59 (suppl. 209). 
8. Snyder, F., J. A. Hobson, D. F. Morrison, and F. Goldfrank. Changes in respiration, heart rate, and systolic blood pressure in human sleep. J. appl. Physiol. 1964, 19, 417.

9. Bellville, J. W., W. S. Howland, J. C. Seed, and R. W. Houde. The effect of sleep on the respiratory response to carbon dioxide. Anesthesiology 1959, 20, 628.

10. Forrest, W. H., Jr., and J. W. Bellville. The effect of sleep plus morphine on the respiratory response to carbon dioxide. Anesthesiology 1964, 25, 137.

11. Robin, E. D., R. D. Whaley, C. H. Crump, and D. M. Travis. The nature of the respiratory acidosis of sleep and of the respiratory alkalosis of hepatic coma (abstract). J. clin. Invest. 1957, 36, 924.

12. Robin, E. D. Some interrelations between sleep and disease. Arch. intern. Med. 1958, 102, 669.

13. Trask, C. H., and E. M. Cree. Oximeter studies on patients with chronic obstructive emphysema, awake and during sleep. New Engl. J. Med. 1962, 266, 639.

14. Kory, R. C., J. Rankin, G. L. Snider, and J. F. Tomasefski. Clinical spirometry. Recommendations of the Section on Pulmonary Function Test- ing, Committee on Pulmonary Physiology, American College of Chest Physicians. Dis. Chest 1963, 43, 214.

15. Severinghaus, J. W., and A. F. Bradley. Electrodes for blood $\mathrm{pO}_{2}$ and $\mathrm{pCO}$, determinations. J. appl. Physiol. 1958, 13, 515.

16. Loomis, A. L., E. N. Harvey, and G. Hobart III. Cerebral states during sleep, as studied by human brain potentials. J. exp..Psychol. 1937, 21, 127.

17. Simon, C. W., and W. H. Emmons. EEG, consciousness and sleep. Science 1956, 124, 1066.

18. Ostle, B. Statistics in Research. Ames, Iowa State University Press, 1963.

19. Brackett, N. C., Jr., J. J. Cohen, and W. B. Schwartz. Carbon dioxide titration curve of normal man. Effect of increasing degrees of acute hypercapnia on acid-base equilibrium. N. Engl. J. Med. 1965, 272, 6.

20. Keele, C. A., and E. Neil. Samson Wright's Applied Physiology, 10th ed. London, Oxford University Press, 1961, p. 135.

21. Fowler, N. O. Effects of pharmacologic agents on the pulmonary circulation. Amer. J. Med. 1960, 28, 927.

\section{SPECIAL NOTICE TO SUBSCRIBERS}

Post Offices will no longer forward the Journal when you move.

Please notify The Journal of Clinical Investigation, Business Office, 10 Stoughton Street, Boston, Mass. 02118, at once when you have a change of address, and do not omit the Zip Code number. 